\title{
Geosciences
}

http://dx.doi.org/10.1590/0370-44672015680024

\author{
Eduardo Gomes dos Santos \\ Doutorando \\ Programa de Pós Graduação, \\ em Geologia - PPGL, \\ Universidade Federal do Rio de Janeiro - UFRJ \\ Rio de Janeiro - Rio de Janeiro - Brazil \\ edudgs@gmail.com
}

\section{The kimberley process certification system - KPCS and diamond production changes in selected African countries and Brazil}

\begin{abstract}
After more than a decade since its creation, the KPCS is undergoing questioning as to efficiency in combating the irregular trade of diamonds, among the countries with significant production for the global market, mainly Angola, the Democratic Republic of the Congo and Zimbabwe. Governments and institutions are considering it to be conducive to serious violations of human rights. In Brazil all activities of the sector have been reduced drastically. It is estimated that there has been a loss in Brazilian production, after implementation of the KPCS rules, in the order of 8.1 million Kts, valued at more than $\$ 2.0$ billion.
\end{abstract}

Keywords: Diamonds; Kimberley Process Certification System - KPCS; Mining.

\section{Introduction}

In the 90's, the illegitimate trade of diamonds became the main source of financing rebel groups in armed conflicts, especially in Angola, the Democratic Republic of the Congo, Sierra Leone and Liberia, who were involved with this trade to support the rebels in Sierra Leone. These rebel groups controlled the diamond mining regions, using the profits to buy weapons and imposing brutal atrocities against unarmed civilians.

The United Nations has adopted several resolutions, between 1993 and 2001, imposing embargoes and sanctions on the trade in arms and diamonds in these Nations. In response, the industry joined forces with Governments and civil society organizations to form an initiative which culminated in the creation of the Kimberley Process certification scheme - KPCS or, in abridged form, Kimberley Process - KP, implemented in 2003.

At this same time, another significant event was related to the United States, which faced problems with the diamond price control exercised by the De Beers Group. As a result, in the year of 1994, the Federal Court of the State of Ohio USA, sentenced De Beers for criminally conspiring to fix diamond prices, having been banning them from dealing in the country. Only at the end of 2003, after agreement and payment of a fine of $\$ 10$ million, did the company re-enter this important market. Note that to this day, the United States represents the largest market for diamonds, which in 2003, in the jewelry sector, its participation was greater than $50 \%$ of the world's total, with a value of around \$ 15.00 Billion (Diamond Trade Company - DTC. Available at: http://www.debeersgroup.com/operations/sales/diamond-trading-company). Currently this leadership revolves around $35 \%$, due to the growing participation of greater China (Antwerp World Diamond Center - AWDC. https://www.awdc.be/ en/homepage).

With the events in African countries apparently shifted, it is believed that the antagonism between the U.S. Government and the DeBeers COMPANY fostered by the American Government, interference in the UN Security Council, because of its recognized influence.

Brazil became part of the KPCS after the 2nd Annual Conference of the Kimberley Protocol, held in South
Africa, initially through the Provisional Measure $\mathrm{N}^{\circ} 125$ of July 30, 2003 and subsequently by means of law $\mathrm{N}^{\circ} 10.743$ of October 9, 2003.

For world mining, the diamonds represent a limited role, unlike other extractive sectors such as ferrous mineral or oil and gas, and are not of strategic importance. However, it creates a huge volume of paying jobs, not only in producing countries, but at several lapidation centers in countries such as India, the United States of America and Israel, or in specialized trade centers as in the cities of Antwerp, London, New York and Tel Aviv. "Global sales of diamond move currently values in excess of the $\$$ 72 billion annually. The sector employs, directly or indirectly, approximately 10 million people around the world, from mining to final sale on jewelry, passing by the trade of the stones ' raw' and by stoning ". (The Diamond Industry Fact Sheet, wdc-w304-Online:. http://www. diamondfacts.org/Diamond_Mining_Environment).

Figure 1 presents the values moved by each sector of the diamond industry and the approximate number of compa- 
nies acting in each.

It should be noted that Zimbabwe had a very small production, a fact that has changed during the following years, directly affecting the credibility of the KPCS.

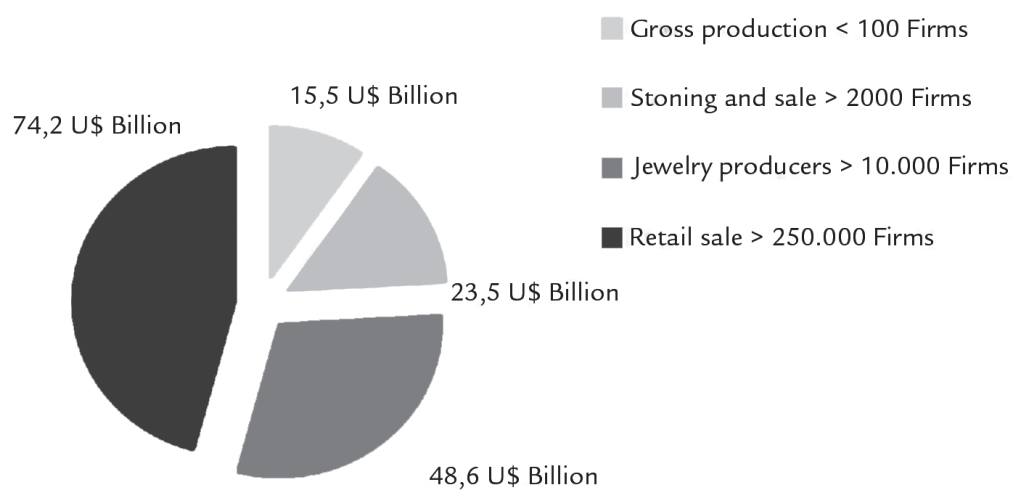

2. KPCS and the system of diamond industry warranties

KPCS is essentially a certification system for import and export trade operations, which require the Member States certifying that the rough diamonds exported from their territory, are free of conflicts. So-called blood or conflict diamonds are defined for this Protocol, as described in resolutions of the UN Security Council - UNSC as:

"Diamonds that originate from areas controlled by forces or factions opposed to legitimate and internationally recognized Governments, and are used to fund military action against these, or are in contravention of with the decisions of the Security Council."

The country members of $\mathrm{KP}$ are obliged to enact legislation complying with that certification scheme, must plan a control system able to eliminate the presence of conflict diamonds in its territory and can only trade with the other Contracting States. Being also required is the adoption of broader measures in diamond producing countries from secondary (alluvial) deposits, including Brazil, where diamonds are geographically dispersed, sparse along fields and riverbeds, operated with simple tools,

\section{Reserves and production}

In 2014, the world's diamond reserves were estimated at 730 million Kt's, according to the data contained in the Mineral Commodity Summaries - 2015 of the USGS. Australia is the country that holds the largest reserve (250 million), followed by the Democratic Republic of Congo (150 million) and Botswana known as artisanal mining, which occurs especially in Sierra Leone, Republic of the Congo and Angola; the protagonists of these conflicts.

The participation in the Protocol is voluntary, but since almost all diamonds traded originate in the signatory States of the KP, the participation becomes practically mandatory for any country wishing to do business in the global market of diamonds. In this way, the price of diamonds exported from a non-member would be drastically inferior to those in the legal market of diamonds, legitimized by the $\mathrm{KP}$. The diamond industry is represented by the World Diamond Council - WDC, and civil society organizations are represented by Global Witness and Partnership Africa-GW Canada-PAC, the two NGOs who worked intensively for the creation of the PK, being its chief monitors.

Although KP was supposedly created to protect the human rights of civilians, the definition does not extend to human rights violations committed by the Member States, even if these abuses are financed by industrial sectors.

Effectively, KPCS covers only international commercial transactions involving rough diamonds. In this way KP does not cover exportation of polished diamonds, leaving a gap that allows the free trade of polished diamonds, sometimes with possible human rights violations. However, in compliance with the standards agreed, WDC has established their own certificate of warranties for the entire industrial sector of diamonds, which applies to all sales occurring in the territorial limits of a country.

The certificate must accompany all transactions through the supply chain for traders, lapidaries, resellers and manufacturers. Such a system clearly shows itself ineffective because of the character of the Congregation of common interests, therefore without the necessary exemption.

"The US diamond jewelry retail sector, which accounts for over half of global diamond jewelry retail sales, was not carrying out the basic steps of the system of warranties. In an earlier report, Global Witness reported similar disappointing results in a survey of diamond jewelry retailers in the UK, US, Australia, Belgium, France, Germany, Italy, and Switzerland. (Global Witness. Oct. 2004)."
(130 million). The KPCS countries produced 130,482,194.63 Kt's for a total of US $\$ 14,085,172,323.57$ averaging US\$ $107.95 / \mathrm{Kt}$, being the second highest average recorded during the period of the KPCS. Zimnisky (2015, pp. 1), based on an analysis of 54 major diamond mines in the world, indicates that for 2015, global production of 153 million kts is expected. Brazilian stocks are estimated at 13.5 million Kt's (Summary in MineralDNPM/2014), considering the possible reserve of mining, declared by the holders of mining concessions, representing approximately $1.8 \%$ of the world's reserves. Table 1 presents the main dia- 
mond producers in the world, depicting the decade preceding the KPCS, 1993 to 2003 .

According to information provided by the DNPM and USGS, the annual average of the Brazilian production, in the period, was $900,000 \mathrm{Kt}$ 's, representing $1.49 \%$ of the cumulative global production, occupying the 9 th position among producers, corresponding to a reduced portion of the world's production. However, this is significant and is close to its historical average for the previous two decades (1980 to
2003), which was $832,000 \mathrm{Kt}$ 's. After the adoption of the KPCS rules in Brazil, production went into steep decline, making in an irrelevant part of this market, falling to $167,000 \mathrm{Kt}$ 's, and accentuating during the last six years, currently less than 50,000 Kt's/year.

Production of rough diamonds-gem and near gem quality by country $x 1000 \mathrm{KTs}$

\begin{tabular}{|c|c|c|c|c|c|c|c|c|c|c|c|c|}
\hline País & 1993 & 1994 & 1995 & 1996 & 1997 & 1998 & 1999 & 2000 & 2001 & 2002 & 2003 & $\sum \%^{1}$ \\
\hline Angola & 130 & 270 & 2.600 & 2.250 & 1.100 & 2.400 & 3.360 & 3.914 & 4.653 & 4.520 & 4.770 & 4.48 \\
\hline Austrália & 18.844 & 19.485 & 18.300 & 18.897 & 18.100 & 18.400 & 13.403 & 11.956 & 11.779 & 15.142 & 14.900 & 26.86 \\
\hline Botswana & 10.310 & 10.550 & 11.500 & 12.400 & 15.100 & 14.800 & 17.200 & 18.500 & 19.800 & 21.300 & 22.800 & 26.06 \\
\hline Brazil & 1.600 & 900 & 1.300 & 800 & 900 & 900 & 900 & 1.000 & 700 & 500 & 500 & 1.49 \\
\hline Canada & - & - & - & - & - & 278 & 2.429 & 2.534 & 3.716 & 4.984 & 11.200 & 3.75 \\
\hline CAR & 370 & 400 & 400 & 350 & 400 & 330 & 311 & 346 & 337 & 311 & 300 & 0.57 \\
\hline C. D'ivoire & - & 80 & 52 & 202 & 207 & 207 & 270 & 210 & 207 & 204 & 205 & 0.27 \\
\hline R D Congo & 2.006 & 4.000 & 4.000 & 3.600 & 3.000 & 3.300 & 4.120 & 3.500 & 3.640 & 4.400 & 5.400 & 6.12 \\
\hline Ghana & 106 & 118 & 126 & 125 & 664 & 640 & 546 & 792 & 936 & 770 & 800 & 0.84 \\
\hline Guyana & - & - & - & - & - & - & 45 & 82 & 179 & 248 & 250 & 0.12 \\
\hline Liberia & - & - & 60 & 60 & 80 & 150 & 120 & 100 & 100 & 48 & 36 & 0.11 \\
\hline Namibia & 1.120 & 1.312 & 1.382 & 1.402 & 1.345 & 1.394 & 1.630 & 1.450 & 1.487 & 1.350 & 1.650 & 2.32 \\
\hline Rússia & 8.000 & 8.500 & 10.500 & 10.500 & 10.500 & 11.500 & 11.500 & 11.600 & 11.600 & 11.500 & 12.000 & 17.60 \\
\hline S. Leona & 80 & 155 & 113 & 162 & 300 & 200 & 7 & 58 & 167 & 147 & 214 & 0.23 \\
\hline Sth. Africa & 4.600 & 4.340 & 5.070 & 4.400 & 4.500 & 4.300 & 4.000 & 4.320 & 4.470 & 4.350 & 5.070 & 7.39 \\
\hline Venezuela & 146 & 203 & 228 & 99 & 158 & 100 & 59 & 29 & 14 & 46 & 30 & 0.16 \\
\hline $\begin{array}{l}\text { Zimbab- } \\
\text { wue }\end{array}$ & - & 104 & 114 & 300 & 321 & 40 & 15 & 8 & - & - & - & 0.13 \\
\hline Other & 288 & 983 & 655 & 425 & 416 & 501 & 785 & 901 & 815 & 880 & 775 & 1.15 \\
\hline TOTAL & 47.600 & 51.400 & 56.400 & 57.100 & 56.600 & 59.500 & 60.700 & 61.300 & 64.600 & 70.700 & 82.900 & 668.700 \\
\hline
\end{tabular}

Diamonds Production in decade preceding the KPCS.

${ }^{1} \sum \%$ - Participation in world production accumulated in the period.

\section{A brief history}

In the year 1994, according to the USGS, world production of natural diamonds totaled 111 million carats, with 52.3 million Kt's distributed between diamonds and gems, and the rest were industrial diamonds, being $80 \%$ controlled by De Beers, whose sales reached US\$ 4.25 billion, with an estimated stock for the same year of $\$ 4.38$ billion.

"With these stocked diamonds, De Beers was able to create an artificial scarcity that allowed him to manipulate the price of diamonds around the world. De Beers sells diamonds through the Diamond Trading Company-DTC, based in London, which sells its diamonds to a select number of buyers, through auctions conducted ten times a year". (MINERAL YEAR BOOK. " Gemstone". 1994).

However, the credibility of this industry suffered from revelations that brutal civil wars in Africa, involving the mass murder and maiming of civilians, were being financed with the sale of rough diamonds. Kantz (2007, pp. 2) summarizes: "the international community took his first steps to curb the trade in diamonds from conflict areas by the end of the 90's".
In July 1998, the UN Security Council, through resolution $\mathrm{N}^{\circ} \mathrm{S} /$ RES/1173, imposed an embargo on all rough diamonds exported from Angola without an official government certificate, affecting the diamonds produced by UNITA (National Union for the Total Independence of Angola) that financed its war effort through the control of about $70 \%$ of Angola's diamond mines. The NGO Global Witness, based in London, edits, in December 1998, an article titled the Rough Trade documenting massive violations of UN sanctions imposed against UNITA. 
The publication directly accused De Beers, which controlled more than $80 \%$ of world production; Belgium, which held the capital arising from the trade of diamonds in the world through the trades carried out by Diamond Exchange in Antwerp (Antwerp World Diamond Centre-AWDC) and several other Nations for trade in diamonds produced by UNITA, under UN sanctions. In their arguments against De Beers, the ' Global Witness ' stated: "It's time for a company that operates in mysterious ways as a family business, re-evaluate its operation and accept that corporate responsibility is an important factor for international business."

According to Shor (2005, pp. 205), the end of the Soviet regime, allowed a large stock of rough diamonds, formerly under the control of officials of the Government of Russia, to enter the market and, yet, with the temporary truce in Angola's civil war, during the 90's, opportunities for thousands of miners (many of whom were recently demobilized soldiers) to mine diamonds in alluvial deposits were created. Suddenly hundreds of thousands of carats of diamonds, typically of better quality, were being sold through offices in Luanda and Antwerp. The Diamond Trading Company - DTC; a commercial subsidiary of De Beers, reportedly bought over US\$ 600 million of these goods to

\section{Discussion}

Today the flow of conflict diamonds on the world market is significantly reduced to less than $1 \%$ (http://diamondfacts.org/index.php) or, considering information from the KPCS Committee itself, this index registers only $0.2 \%$ of diamonds in the global market with a possible origin in areas of conflict However, it remains extremely difficult to accurately quantify the current levels of illicit diamonds flowing in the global trade, both for historical reasons and the very definition of conflict diamonds. Traditionally the KP defines conflict diamonds as; 'only those that finance conflicts fought by rebel groups against Governments'. Therefore the KP has not counted as conflict diamonds produced in areas of relative stability, or even in those where changes to the policy framework, that have occurred over time, give a character of legitimacy to these conflicts, as in the striking example of production of the Marange fields in Zimbabwe.

From the implementation of the remove them from the market (and thus kept prices stable) in 1996. This decision caused a surge in stocks of diamonds from De Beers, causing severe criticism in the financial community. As a result, the Argyle mine executives (Rio Tinto Co.) adopted the decision not to renew its contract with DTC marketing. Furthermore, the discovery of diamonds in Canada introduced a rival mining company, BHP Billiton, in the diamond market, thus creating a new channel of distribution outside of the De Beers control.

At the end of 1999, the alert against the diamonds in conflict gained momentum. The Global Witness joined the German NGO Medico International and two other important Dutch NGOs (Netderlands Institute Voor Zuldelijk Afrika-NIZA and Oxfam NetherlandsNOVIB), in a public awareness campaign called Fatal Transactions that sought to raise awareness of the consumer about conflict diamonds. For fear of suffering reprisals, legitimate producers of African conflict-free diamonds, such as South Africa and Botswana, argued that the campaign did not prevent consumers from buying diamonds, but that they should be informed about the origin of the products that they bought.

In Brazil, diamonds have been continuously produced and marketed since the early 18 th century. From the

KPCS until the year 2013, whose data are available, few changes have occurred in the primary sector of diamond production, with emphasis on the entry of Zimbabwe. However, even with the addition of production of 10.411 million ct's in the year 2013 from the Marange fields located in the southeast of the country, world production has not changed significantly during the period of validity of the KPCS, being approximately 150 million in 2003, achieving a maximum of 175,917,823.48 carats in 2006 - period pre-global financial crisis - and currently stabilizing at around 130 million carats, reflecting a possible control of prices by controlling supply.

Figure 2 presents the production of the major African countries, formerly involved with the production of conflict diamonds. Note that the Democratic Republic of Congo and South Africa have similar behaviors with regard to the proportionality of the decline of their pro- largest producer during the colonial period (1729-1822) and part of the Empire (1822-1889), "favored by the abundance of mines and by extensive use of slave labor" (Cassedanne. 1989. pp. 326. ), Brazil currently has become an irrelevant producer in the global market.

The Technical Report No50Diamond Profile (Gem and Industrial Diamond), was developed for the Decennial Plan 2010-Duo-Mining 2030 (MME/SGM-2009); lists the prices of diamonds from some deposits in Brazil, being:

"The quality of the diamonds in alluvial deposits in Brazil is high and therefore achieves market prices, between $\$ 100.00$ and $\$ 400.00$ per carat. The exceptions are for the secondary deposits of Juina, Mato Grosso, where the average value of diamonds "run of mine" reaches a maximum of $\$ 25.00$ per carat: However, it sporadically recovers large diamonds of the highest quality that are worth extremely high values. In alluvial rivers, mainly Santo Antônio do Bonito and Santo Inácio, in the Coromandel region in Minas Gerais, very large stones, of high quality, with a very high market value are frequently recovered. For the diamonds coming from kimberlites, the prices range from $\$ 20.00$ per carat in Juina, up to $\$ 170.00$ in Canasta 1 "

ductions. The DRC is a medium volume of production around 30 million carats per year, at the beginning of the Decade of the years 2000, for a production of approximately 20 million carats in the year 2013, with an estimated loss of 60 million carats during this period. As for South Africa, it went from a production of more than 17 million carats per year to 7 million carats in 2013; on average, there was an estimated loss of 50.00 million carats for that period. Among other reasons, a considerable part of the changes observed in these volumes may have occurred because of mine exhaustion or financial infeasibility of deposits, due to the end of the incorporation of irregular production from Angola, fed through the various routes of smuggling (Global Witness. 1998, op. cit.). While, on the other hand, Angola presents slightly higher production due to the relative political stability achieved during the period.

In Zimbabwe, with deadpan pro- 
duction in period prior to the KPCS, which was under constant monitoring due to successive allegations of human rights violations, shows from 2009 a growing production. However, this production is currently in freefall. Note that this decline is due to the difficulty of financial and technological transitions that no consists of mining in inconsistent rocks, gravels and superficial conglomerates at deeper levels in the rocks. Zimnisky (2015) considers questionable the economic viability of these deposits, under these new conditions, and indicates for 2014 a production of 8-12 million carats, suggesting a production of less than one million Kts/

Figure 2

Production of the

African countries involved with conflict diamonds, during the KPCS. Source: SCPK and USGS (2003 - 2014).

African countries, already related to conflict diamonds but with reduced participation in the total world production, presented various behaviors, as shown in Figure 3. Ghana, despite never having suffered anyone UN sanction, figured on the routes of diamonds coming from UNITA areas to Europe. Likewise, as occurred with the production of the DRC and South Africa, a decline in its production with the end of the incorporation of this irregular production from year for the next few years.

Whereas world production presents a similar behavior to a stochastic system, even with the sudden entry of the Zimbabwe production, and it has not moved away from the annual average of production. Recognizing that this parameter cannot be considered absolute for an accurate indication of the volumes smuggled, it can, however, from the learned knowledge and empirical perspective, be admitted as valid to scale the order of magnitude of the correlated production volumes of illicit mode to this particular region of conflicts.

As for the estimation of the financial volumes, it is still harder to be certain. It is considered that only the average carat value of diamond smuggling, independent of any monetary correction, tends to be higher than the average carat value produced and marketed today by incorporating the risk factors present at the time because they are ultimately reflecting the use of the best quality diamonds, and therefore, are those of higher value. Currently, these countries account for $52.7 \%$ of the production of gem quality diamonds. It can be affirmed that the scheme of the KPCS has impacted positively on the primary production of diamonds in their territories, with reflections on the global market.

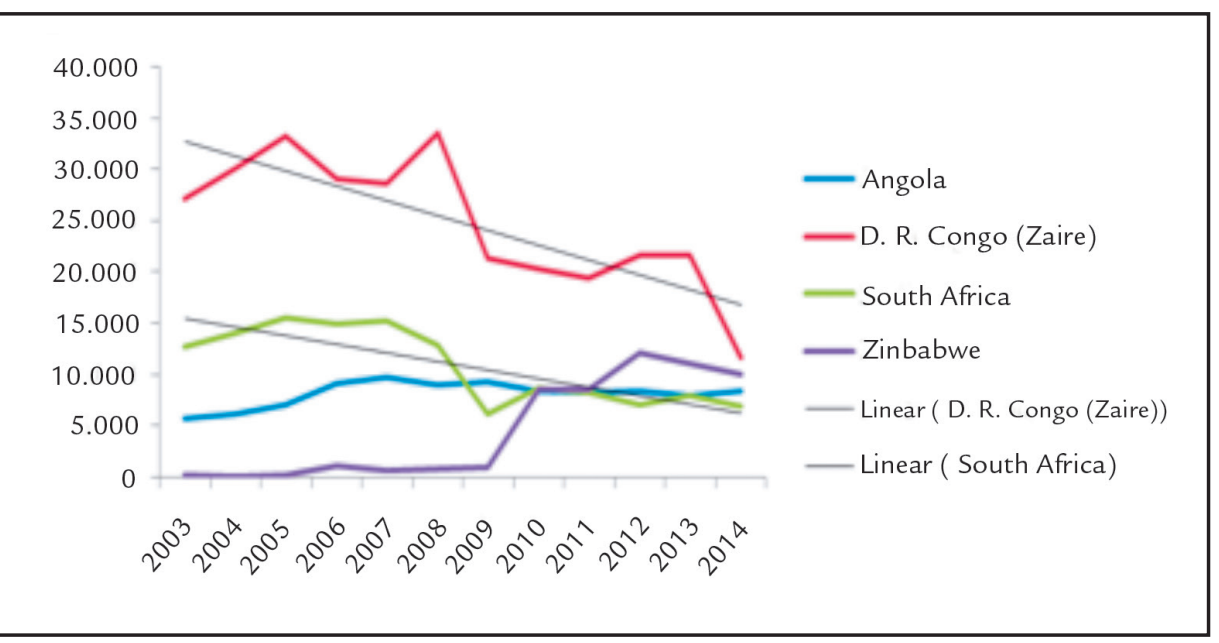

Angola, but in much smaller volumes, declined from an average production of one million carats per year before the KPCS, to approximately 200,000 carats in 2013. Sierra Leone and Liberia remain with relatively stable production, reflecting the social and economic recovery efforts in those countries, as mentioned earlier. While in the Ivory Coast continues with their production suspended by KPCS since 2007 , there are hopes of re-structuring the industry that allows this activity.

Also included in the framework are Brazil and Venezuela. Venezuela never presented significant production and withdrew voluntarily from the KPCS, preventing their expulsion. Currently, these countries account for only $0.68 \%$ of the production of gem quality diamonds, being that the KPCS regime helped industry ordering, assisting economic and social development of these countries, as discussed.
Figure 3

Production of other

African countries and Brazil and Venezuela. Source: SCPK and USGS (2003 - 2014).

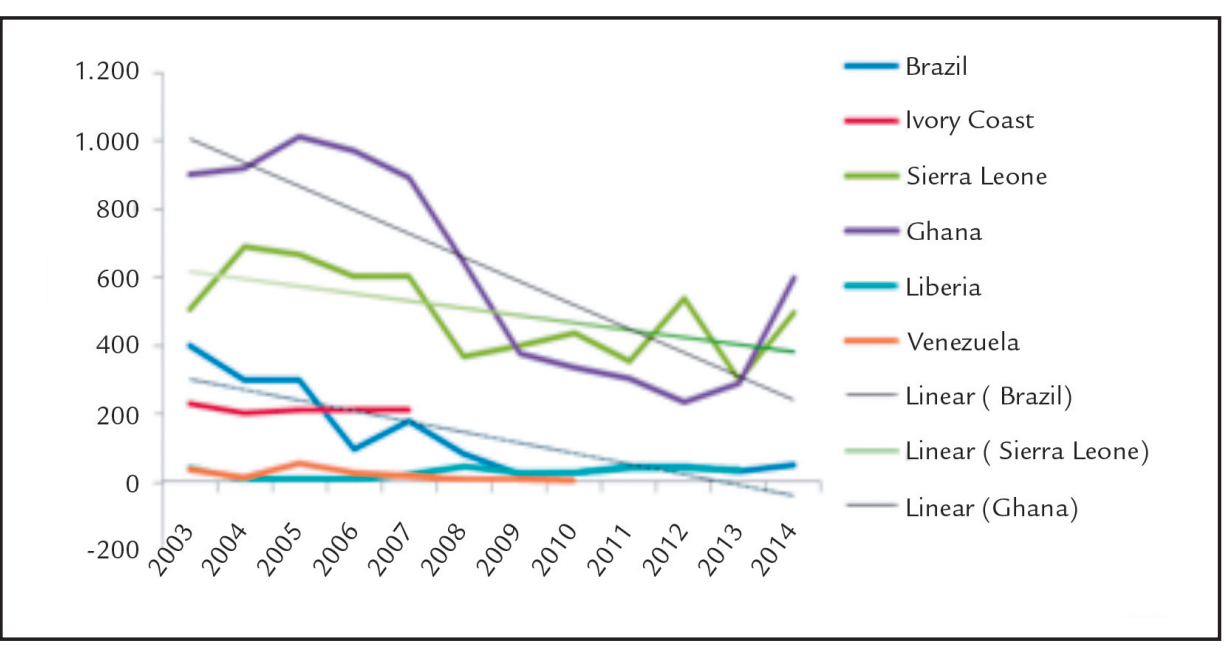




\section{Conclusions}

It is observed that although the KPCS has been created to protect the human rights of civilians, the definition does not extend to human rights violations committed by the Member States, even if these abuses are financed by industrial sectors, such as in Zimbabwe.

The pacification of diamond production in Angola and the DRC, who were important producers involved with conflict diamonds, occurred because of the pressures exerted by NGOs, which associated the crimes committed at the source of the diamonds with the end market jeweler, and undoubtedly the legislation enforced by KPCS. However, as pointed out by Shor (2005. Op. Ct.), political and economic forces mobilized, before and at the beginning of the KPCS, were important for changing that scenario

The clash between De Beers and the Government of the United States, dissatisfied with the price controls exercised by the company, caused De Beers to restructure itself, precipitated by factors not related to conflict diamonds, such as; the disruption of Australia (Rio Tinto co.) with the DTC, the entry of Canada as new producer of diamonds on a global scale and outside the control of De Beers, and; furthermore, the end of the USSR which enabled the placing of a large volume of rough diamonds in this market.

As reported, the production of countries with restrictions of KPCS or under UN sanctions, added $0.68 \%$ to global output, which allows a questioning about the need of the current interference in this market.

For Brazil, the observance of requirements of the KPCS has impacted not only the primary production as the entire industry. The total disorganization of activity is evident with the collapse of the activity upon failing to meet the KPCS regulations. In summary, the KPCS imposed control and, in response, there have emerged various crimes such as; smuggling; illegal production; invasion of indigenous lands and environmental reserves; disrespect to environmental legislation; robberies; deaths and other crimes.
From the beginning of the KPCS until the end of 2013, for whose years data are available, it is estimated a production loss of more than 8.1 million carats. As the entirety of this production comes from secondary deposits and adopting the mean of the values reported in the technical report $\mathrm{N}^{\circ} .50$ (MME/ SGM - 2009) of around US\$250.00/ $\mathrm{Ct}$, an estimated US\$2.0 billion has been lost only in the primary sector of production. The stoning, with its potential to add value to the rough stones, is also in sharp decline in Brazil. According to the Centro de Tecnologia Mineral (CETEM), in 2009, the total number of the employed workforce, directly in the production chain of diamonds amounted to 624 , far below the 3919 employees at the end of the 80's.

Currently its participation in the production of diamond gems is irrelevant, in the order of $0.04 \%$. It can be affirmed that Brazil was the only country to have undergone negative consequences because of the KPCS.

\section{References}

ANNUAL GLOBAL SUMMARY: 2004 - 2013. Production, Imports, Exports and KPC Counts. Available at: http://www.kimberleyprocess.com.

BAIN \& COMPANY. In: Antwerp World Diamond Centre - AWDC. Private Foundation. The Global Diamond Report. 'Journey through the Value Chain'. 2013.

CASSEDANNE, J. P. Diamonds in Brazil. The Mineralogical Record, v. 20, n.5, 1989.

CENTRO DE TECNOLOGIA MINERAL - CETEM / Ministério da Ciência e Tecnologia - MCT. Mineral Data. Available at: http://www.cetem.gov.br/.

CONGRESS OF UNITED STATES OF AMERICA. Public Law 108-19-APR. 25, 2003117 STAT. 631. 108th Congress. (http://www.treasury.gov/sanctions/Documents/pl108_19.pdf).

DEPARTAMENTO NACIONAL DE PRODUÇÃO MINERAL - DNPM. Sumário Mineral Brasileiro - "Diamante". 2001 - 2014. Available at: http://www.dnpm. gov.com.br.

DEPARTAMENTO NACIONAL DE PRODUÇÃO MINERAL - DNPM/MME/ SGM. Plano duo-decenal (2010 - 2030) de geologia e mineração. Relatório Técnico $\mathrm{N}^{\circ}$ 50. "Perfil do Diamante (Gema e Diamante Industrial)", 2009.

GLOBAL WITNESS. "A Rouge Trade. The Role of Companies and Governments in the Angolan Conflict". 1998. Available at: http://www.globalwitness.org/sites/ default/pdfs/A_Rough_Trade.pdf.

KANTZ, C. The power of socialization: engaging the diamond industry in the Kimberley Process. Business and Politics. v. 9. Iss. 3. Article 2, 2007.

KRAWITZ, A. Rapaport Magazine. Trade Report. Aug. 2013 and Feb. 2014. Available in: http://www.diamonds.net/Magazine/Article.

MENZIE, W. D. et alli. Review of selected global mineral industries in 2011 and an outlook to 2017. U.S. Geological Survey. p. 32, 2013. (Open-File Report - 1091).

PARTNERSHIP AFRICA CANADA - PAC. "Fugitives and Phantoms: The Diamond Exports of Brasil". Occasional Paper n ${ }^{\circ}$ 13. Editor: Shawn Gerald Blore. Apr. 2006.

PARTNERSHIP AFRICA CANADA - PAC: "Other Facets". The Kimberly Process Derails Over Zimbabwe. Aug/2011. 
PORTO FILHO, F. J. da S. "A interferência da ONU na soberania brasileira. O processo do certificado de Kimberley para diamantes brutos no mercado internacional e a jurisdição de controle da legalidade pela Justiça Federal”. Jus Navigandi. Year 15, nº 2652, oct. 5. Teresina - Pi, 2010.

SHOR, R. "A Review of the Political and Economic Forces Shaping Today's Diamond Industry”. Gems \& Gemology, Vol. 41, Nº.03, pp 202-233. GIA, Fall 2005.

SMILLIE, I. et alli. "The heart of the matter Sierra Leone, Diamonds \& Human Security”. Partnership Africa Canada - PAC Ottawa, Canada. January 2000.

UNITED NATIONS - UN. General Assembly: Resolutions: (A/Res/55/56; A/ Res/56/37; A/Res/56/263 and others). Available at: http://www.un.org/en/docs/ga/ quick/regular/56.

US GEOLOGICAL SURVEY. Minerals Yearbook. Vol.I. “Gemstones”. 2004 - 2015.

US. GEOLOGICAL SURVEY. Mineral Commodity Summaries. Diamond/Industrial, pp. 51. 2015.

WORLD DIAMOND COUNCIL - WDC. DIAMONDSFACTS.ORG. Fact \# 10. "More than $99 \%$ of diamonds are now from conflict free sources and traded under the un-mandated kimberley Process". Available at: http://diamondfacts.org/index. php.

ZIMNISKY. P. "Global Rough Diamond Production Estimated to Hit Over 135 M Carats in 2015”. Diamond Industry Analysis. Mining Weekly. Feb 2015.

Received: 20 February 2015 - Accepted: 06 July 2015 